\title{
Obstructive Sleep Apnea and Hypertension: Updates to a Critical Relationship
}

\author{
John Brown ${ }^{1} \cdot$ Farshid Yazdi ${ }^{2}$ Mona Jodari-Karimi ${ }^{1}$. Jonathan G. Owen ${ }^{3} \cdot$ Efrain Reisin $^{2}$ \\ Accepted: 2 February 2022 / Published online: 5 March 2022 \\ (c) The Author(s), under exclusive licence to Springer Science+Business Media, LLC, part of Springer Nature 2022
}

\begin{abstract}
Purpose of Review Obstructive sleep apnea (OSA) is an underdiagnosed illness linked to essential hypertension (HTN), resistant hypertension ( $r-H T N)$, and cardiovascular disease (CVD). This review provides updates on the epidemiology, pathophysiology, and treatments of OSA-associated HTN.

Recent Findings Mild sleep apnea increases the risk for HTN. Eighty-nine percent of young patients aged 18-35 with HTN not attributed to secondary causes have underlying OSA. Home sleep studies are noninferior to formal polysomnography for OSA diagnosis. Nocturnal oxygen desaturation rate is positively correlated with HTN severity. Gut microbiome neocolonization in response to high-fat diet cravings in patients with OSA alters immune function and worsens HTN. Carbonic anhydrase inhibitors and probiotics show newfound potential for OSA-associated HTN treatment. OSA recognition improves hospital outcomes after a STEMI. Hypoxia-inducible factor (HIF) transcription increases in a dose-dependent manner to hypoxia, and HIFs are strongly linked to cancer growth.

Summary OSA and HTN are comorbid conditions with adversely connected pathophysiology including sympathetic hyperactivity, gut dysbiosis, proinflammation, endothelial damage, rostral fluid shifts, pharyngeal collapse, intravascular fluid retention, nocturnal energy expenditure, and metabolic derangements. The dose-response effect of OSA on HTN severity challenges blood pressure $(B P)$ control, so those with refractory HTN should be screened for OSA.
\end{abstract}

Keywords Obstructive sleep apnea (OSA) · Apnea-hypopnea index $(A H I) \cdot$ Sleep-disordered breathing (SDB) Hypertension · Resistant hypertension · Gut dysbiosis

\section{Introduction}

OSA is a respiratory condition in which pharyngeal airway collapse causes brief, episodic reductions in intrathoracic airflow while sleeping. This results in cyclical oxygen desaturation,

This articleis part of Topical Collection on Sleep and

Hypertension

Farshid Yazdi

fyazd1@1suhsc.edu

1 School of Medicine, Louisiana State University Health Sciences Center, LA 70112 Gravier Street, New Orleans, USA

2 Section of Nephrology, Department of Medicine, Louisiana State University Health Sciences Center, 1542 Tulane Avenue, New Orleans, LA 70112, USA

3 Section of Nephrology, Department of Medicine, University of New Mexico School of Medicine, 2211 Lomas Blvd NE, Albuquerque, NM 87131, USA reflexive sympathetic hyperactivity, frequent microarousals, poor sleep quality, and daytime drowsiness [1]. The soporific effects of OSA decrease quality of life and increase the risk of daytime and workplace accidents. Chronic daytime fatigue results in cravings for energy-dense foods, thus increasing the risk for obesity, dyslipidemia, diabetes, and metabolic syndrome [1]. Patients with OSA are at higher risk for depression, cognitive delay, and mood lability [2]. OSA is associated with numerous cardiovascular derangements, including coronary artery disease, stroke, arrhythmias, peripheral artery disease, heart failure, and HTN [3, 4]. Many patients who suffer from OSA are not timely screened and treated, resulting in early onset of preventable cardiovascular disease (CVD) [4]. The critical relationship between OSA and HTN is discussed in this review.

\section{Diagnosis}

The diagnosis and severity of OSA are based on the apnea-hypopnea index $(A H I)$, which reports the number of 
apneic and/or hypopneic events during one hour of sleep [5••]. Apneic events obstruct $>90 \%$ of intrathoracic airflow, whereas hypopneic events obstruct $>30-90 \%$ of intrathoracic airflow [6]. Both types of events last at least $10 \mathrm{~s}$ and result in oxygen desaturation of 3\% or greater [6]. Mild OSA causes an AHI of 5-14 events/h; moderate OSA causes 15-29 events/h; and severe OSA causes $>30$ events/h [7].

OSA should be suspected in patients with daytime somnolence, poor sleep habits, partner complaints of snoring, obesity, poor quality of life, or failure to achieve $B P$ goals despite antihypertensive medication compliance. Leading risk factors for OSA are obesity, male sex, and old age. Obesity confers the greatest risk, and OSA prevalence is the highest among those with BMI $>35 \mathrm{~kg} / \mathrm{m}^{2}$ [8]. Obesity is also recognized as a strong risk factor for HTN. The effects of OSA on HTN are similar to those of obesity on HTN, independently of one another; each increase in either BMI by $1 \mathrm{~kg} / \mathrm{m}^{2}$ or $A H I$ by 1 event $/ \mathrm{h}$ similarly affects $B P[9 \bullet]$. It has been reported that the female sex steroids progesterone and estrogen increase ventilatory drive, thus reducing the risk for OSA in women compared to men [10]. The aging process reduces carotid chemoreceptor sensitivity, decreases lung function efficiency, and dysregulates respiratory neuronal circuits [10]. Other chronic medical conditions that increase OSA risk include end-stage renal disease (ESRD), congestive heart failure (CHF), chronic lung disease, and craniofacial abnormalities. In the setting of these risk factors, clinical screening identifies patients who should be formally tested for OSA.

\section{Screening Surveys}

Patient surveys used to screen for OSA include the Epworth Sleep Scale, the Berlin questionnaire, and the STOP-BANG questionnaire. The latter has derivatives unique for Arabic and Asian populations [11-14]. Popular among them is the STOPBANG questionnaire, which uses eight questions to gather subjective (snoring, tiredness, observed apnea) and objective ( $B P$, BMI $>35 \mathrm{~kg} / \mathrm{m}^{2}$, age $>50$ years, neck circumference $>40 \mathrm{~cm}$, male gender) data. The survey's diagnostic sensitivities in patients with an $A H I>5$ events $/ \mathrm{h},>15$ events $/ \mathrm{h}$, and $>30$ events $/ \mathrm{h}$ are $83.6 \%, 92.9 \%$, and $100 \%$, respectively [11]. Affirmative answers to each of the eight questions receive one point, and a score $>3$ merits a formal sleep study [12]. In all patients with OSA, concomitant HTN and adequacy of HTN treatment should be frequently investigated. This is particularly important if STOPBANG scoring is $\geq 5-8$, which is highly correlated with moderate to severe OSA and resistant HTN [12].

\section{Polysomnography}

Overnight laboratory polysomnography (PSG) is the diagnostic gold standard for diagnosing OSA [15]. PSG studies analyze positional changes and body movements while sleeping, electroencephalogram (EEG) activity, respiratory rate, quality of breathing, oxygen saturation, $B P$, chest wall movement, and heart rate. Prescriptions for continuous positive airway pressure (CPAP) machines, a mainstay of OSA treatment, are based on the data acquired during sleep studies. Despite their utility, many temporal, environmental, transportation, and financial factors may deter patients from making it to the sleep center for their study. A recent European assessment of PSG challenges reported that the percentage of referred patients who arrived for their sleep study declined from $92.5 \%$ to only $20 \%$ before and after the COVID-19 pandemic, respectively [16].

While PSG remains the traditional standard for OSA diagnosis, modern home-based sleep tests (HBST) are increasing in popularity among both prescribers and patients. HBST are more convenient, less invasive and nearly half the cost of PSG and the diagnostic sensitivities between the two tests are statistically equal [15]. Despite this, CPAP prescriptions occur $15 \%$ more frequently when based on PSG studies, which confers unnecessary treatment costs and inconveniences to patients who would otherwise not require CPAP therapy based on HBST analysis [15]. Hospital quality improvement initiatives aimed at reducing the risk of CVD and resistant HTN among patients could consider increasing HBST prescriptions in lieu of PSG referrals, increasing the likelihood of study completion.

\section{Oxygen Desaturation Rate}

Oxygen desaturation rate (ODR) identifies patients with OSA who are at greatest risk for HTN, and it is a relatively novel datapoint acquired during PSG or HBST. ODR is defined as the change in the percentage of pulse oxyhemoglobin saturation ( $\mathrm{SpO} 2)$ per second after an apneic/hypopneic event [17••]. A 2020 clinical trial including 102 patients with severe OSA identified that fast ODRs correlate with severity of both essential and r-HTN $[17 \bullet \bullet$. The study design defined fast ODR as any value above the average for all 102 participants, whereas slow ODR values were below the overall average. Those with faster ODRs ( $>0.37$ ) had higher systolic blood pressure (SBP) while awake and asleep compared to those with slower ODRs $(<0.37)[17 \bullet \bullet$. The average SBP while awake among those with faster ODRs compared to slower ODRs was $149.9 \pm 18.3 \mathrm{mmHg}$ vs. $131.8 \pm 15.6 \mathrm{mmHg}$, and the average SBP while asleep in the same order was $149.6 \pm 19.9 \mathrm{mmHg}$ vs. $128.7 \pm 15.6 \mathrm{mmHg}$; both $P<0.001$ $[17 \bullet \bullet]$. Additionally, fast ODR correlated with higher short-term $B P$ variance $(15.0 \pm 4.8$ vs. $11.6 \pm 3.6 \mathrm{mmHg}$, $P<0.001)$ and higher prevalence of HTN $(74.0 \%$ vs. $26.9 \%$, $P<0.001)$ compared to slow ODR $[17 \bullet \bullet]$. 


\section{Bidirectional and Dose-Response Relationship}

OSA and HTN exist in a bidirectional relationship such that the presence of one disease increases the risk of the other [18]. Patients may not be diagnosed with both at the time of clinical assessment, but the discovery of one disease merits the investigation of the other. In a 2018 Taiwanese study assessing the prevalence of OSA in a cohort of 215 patients with preexisting HTN, $81.9 \%$ were diagnosed with new onset OSA [4]. A different study using PSG to observe the effects of HTN on sleep characteristics in 304 participants who had no prior diagnosis of OSA found that HTN was associated with decreased sleep efficiency, decreased mean and minimum oxygen saturation during apneic episodes, increased $A H I$, and increased oxygen desaturation index (ODI), which is defined as the number/hour of apneic events resulting in reductions in oxygen saturation by $\geq 4 \%$ from baseline [19]. A 2020 study of 4,500 people with OSA identified that merely mild OSA ( $A H I=11-15$ events/h) increased the likelihood of having HTN by 78\% when compared to control subjects without OSA $(O R=1.779,95 \% \mathrm{CI}$ 1.403-2.256) [20••].

A dose-response relation between OSA and HTN has been previously documented [9•, 21, 22]. The most notable study to characterize this dose-response relationship was published by Peppard et al. in 2000 [22]. In that study, 709 patients with OSA were followed for four years to assess the incidence of new onset HTN among them. After correction for BMI, neck/weight circumference, age, sex, and alcohol/ tobacco use, severity of OSA positively correlated with incidence of HTN. Compared to controls with an $A H I$ of 0 events $/ \mathrm{h}$, odds ratios for mild OSA ( $A H I=0.1-4.9$ events $/ \mathrm{h}$ ), moderate OSA $(A H I=5.0-14.9$ events $/ \mathrm{h})$, and severe OSA $(A H I \geq 15$ events/h) were 1.42 (95\% CI $1.13-1.78), 2.03$ (95\% CI 1.29-3.17), and 2.89 (95\% CI 1.46-5.64), respectively [22]. The most recent data from a 2018 meta-analysis pooling 26 original studies and over 51,000 participants confirmed a dose-response relationship between HTN and mild OSA $(O R=1.184,95 \%$ CI $1.093-1.274, P<0.05)$, moderate OSA $(O R=1.316,95 \%$ CI $1.197-1.433, P<0.05)$, and severe OSA $(O R=1.561,95 \%$ CI $1.287-1.835, P<0.05)$ [21].

\section{Epidemiology}

HTN is the leading risk factor for CVD, stroke, disability, and death, and it affects $31 \%$ of the worldwide population [23]. Its prevalence among patients with OSA increases to $42 \%$ [24]. The Joint National Committee on High Blood Pressure recognized OSA as an identifiable cause of HTN in 2003 [25]. Despite the evident link between OSA and HTN, it has been estimated that $80 \%$ of middle-aged men and women with moderate to severe OSA are undiagnosed with the condition [26], which is partially attributed to poor screening and inconvenience of PSG. Prevalence of OSA is estimated to be $9-30 \%$ overall, $13-33 \%$ in males, $6-19 \%$ in females, and up to $90 \%$ among elderly men [27]. Though age is a considerable risk factor for OSA, young patientsparticularly those with HTN of unknown etiology-remain susceptible. In a cohort of 593 patients aged 18-35 years who were diagnosed with HTN and screened for secondary causes without diagnostic findings, $88.9 \%$ of them had OSA [28••].

OSA is the leading cause of r-HTN [29], which is diagnosed when elevated $B P$ persists despite patient compliance with at least three maximally dosed antihypertensive medications. R-HTN occurs in $12-15 \%$ of all people diagnosed with HTN [30], and an astounding 70-83\% of people with r-HTN also have OSA [31]. R-HTN and OSA have also been studied in the presence of kidney disease. A 2012 study assessing OSA prevalence across various stages of renal function found that sleep apnea occurred in $27 \%, 41 \%$, and $57 \%$ of patients with either a glomerular filtration rate (GFR) $>60 \mathrm{~mL} / \mathrm{min}$, chronic kidney disease not on dialysis, or ESRD on dialysis, respectively [32]. A separate study in 2012 identified that the association between r-HTN and OSA is the strongest in patients with ESRD compared to those with either CKD or normal kidney function [33].

Masked HTN (m-HTN) is defined as elevations in $B P$ that are not diagnostic of HTN in the clinical setting despite being observed in the home setting via ambulatory $B P$ monitoring (ABPM) or one-time at-home monitoring. Home $B P$ recordings that meet the criteria for m-HTN are defined as $B P \geq 135 / 85 \mathrm{mmHg}$, nighttime $B P \geq 120 / 70 \mathrm{mmHg}$, or $24-\mathrm{h}$ average $B P \geq 130 / 80 \mathrm{mmHg}$ [34]. Even minor elevations in $B P$ observed in the clinic may provide a clue to underlying $\mathrm{m}$-HTN - particularly among patients with OSA. In a 2008 study of 130 newly diagnosed OSA patients, those with OSA were 2.7 times more likely to have $\mathrm{m}-\mathrm{HTN}$ when clinic recordings identified $B P>125 / 83 \mathrm{mmHg}$ [35]. Of the 130 patients included in the study, $35.4 \%$ had essential HTN, $30 \%$ had m-HTN, and $3.1 \%$ had white coat HTN. Collectively, $68.5 \%$ of those with OSA had some type of HTN [35], which is higher than the $30 \%$ prevalence of HTN among the general population.

\section{Mechanisms of Disease}

The physiological connections between OSA and HTN are complex and multifactorial. The pathophysiology begins with obstructed airflow into the lungs, which causes transient hypoxia and hypercapnia (Fig. 1). These repetitive blood gas derangements initiate sympathetic overactivity, resulting in nocturnal arousals, fragmented sleep, and spikes 


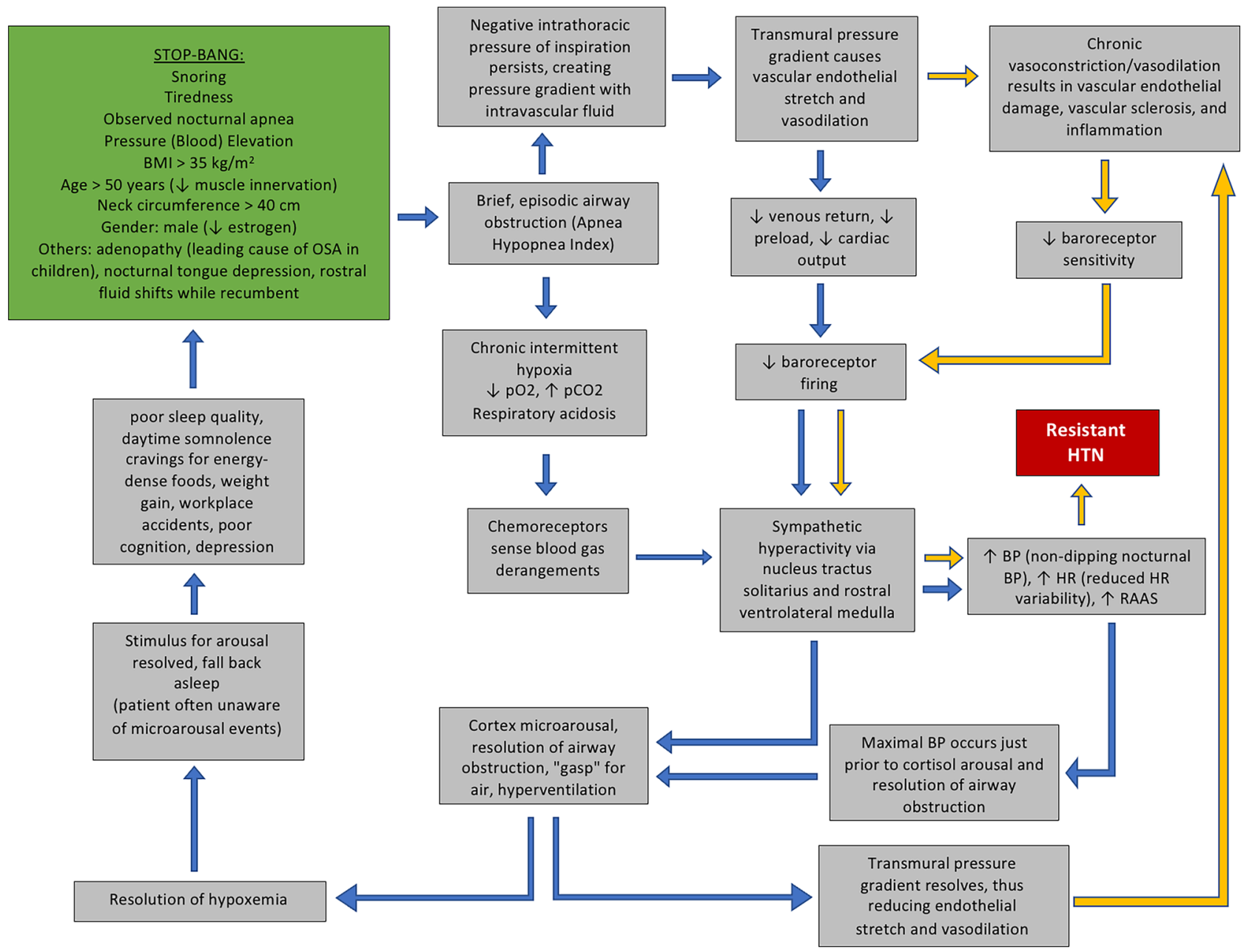

Fig. 1 The connected pathophysiology of OSA and HTN. The green box is the STOP-BANG criteria. Black arrows represent acute physiological occurrences during apneic sleep. Purple arrows represent

in $B P$ [36-38]. The initial insult of hypoxia and sympathetic overactivity contributes to numerous mechanistic alterations that worsen HTN (Fig. 1).

\section{Hypoxia and Sympathetic Nervous Activity}

Anoxia is incompatible with life, so the human body is well adapted to recognizing and correcting transient and chronic hypoxia. When attempted inspiration is interrupted by oropharyngeal obstruction, the negative intrathoracic pressure from diaphragmatic contraction is unable to equilibrate with atmospheric air pressure. The persistence of negative intrathoracic pressure establishes a pathological transmural pressure gradient with the intravascular compartment. Vasodilation occurs in response to this pressure gradient, thus lowering intravascular pressure and reducing right atrial filling pressure. Vasodilation stimulates endothelial baroreceptors to transmit general visceral afferent signals to the long-term physiological changes that result of chronic OSA. These chronic derangements lead to resistant, worsening HTN, which is displayed in the red box

nucleus tractus solitarius in the ventral medulla. Efferent sympathetic nervous activity (SNA) is then increased, resulting in increased heart rate, renin-angiotensin activation, and increased $B P$ [39].

SNA is closely linked to sleep. Twenty-four-hour urinary catecholamine levels, which are markers of SNA, are elevated in correlation with symptoms of OSA including increased sleep onset latency, decreased sleep time, and decreased sleep efficiency [40]. Although the $B P$ can fluctuate during sleep with OSA, the maximal $B P$ corresponds temporally to the moment just prior to the resolution of the apneic episode, which suggests an association between the two phenomena [41]. In normal sleep physiology, SNA decreases during non-REM sleep compared to daytime SNA [42••]. Because non-REM sleep accounts for $80 \%$ of net sleep time, the majority of sleep is appropriately described as restful and restorative with low levels of SNA. Pharyngeal muscle tone, heart rate, and cardiac output are autonomically 
modulated, and they decrease while sleeping due to reduced SNA without causing symptoms of pharyngeal collapse, bradycardia, or severe hypotension, respectively. In abnormal OSA pathophysiology, nocturnal SNA stimulation during apneic events inhibits HR and cardiac output reduction. Nocturnal HR, therefore, exhibits less variability compared to healthy sleepers. This pathological finding correlates with

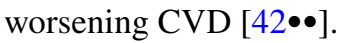

The effects of SNA on BP are well understood. Some antihypertensive agents function by antagonizing adrenergic activity, particularly by blocking beta receptors. SNA preferentially elevates diastolic blood pressure (DPB), whereas elevations in SBP are caused by atherosclerotic, noncompliant arteries. Obesity and apneic events particularly stimulate SNA, thus increasing morning DBP [9•]. In one study using PSG to assess patients who screened positively for OSA, elevations in DBP the morning after PSG could be statistically predicted by two variables, $A H I(\beta=0.14,95 \% \mathrm{CI}$ $0.04-0.25, P=0.007)$ and BMI $(\beta=0.21,95 \%$ CI $0.12-0.32$, $P<0.001)$ [9•]. In addition to CVD and worsening HTN, chronic SNA stimulation while sleeping causes patients to experience daytime anxiety with depressive features, significant fatigue and cravings for energy-dense foods, thus overall reducing patient quality of life.

\section{Non-dipping Phenomenon}

SBP and DBP reduce by $~ 10 \mathrm{mmHg}$ (about 10-20\%) during slumber, but this dipping phenomenon is reversed in those with OSA [35, 43]. The dipping phenomenon occurs when lying recumbent partly because lower leg fluid shifts in the rostral direction, increasing carotid intravascular fluid volume and triggering carotid baroreceptors to reflexively reduce SNA, thus causing a nocturnal "dip" in $B P$. Patients with OSA have elevated SNA from the obstructed airway, thus antagonizing the natural dipping phenomenon and causing intravascular pressure elevations. Overtime, the chronic HTN leads to sclerotic, noncompliant vasculature, decreased endothelial production of vasodilatory nitric oxide, and insensitive baroreceptors-further inhibiting the reflex dipping phenomenon. [43-45]. When carotid artery stenting places chronic pressure upon the relatively insensitive baroreceptors of those with chronic OSA, one study found that $64 \%$ of patients converted from a non-dipping $B P$ pattern to a dipping $B P$ pattern one year after the procedure [46]. A 2018 cross-sectional analysis found a significant association between OSA and nocturnal elevations in SBP compared to daytime SBP (non-dipping) $(O R=3.92,95 \% \mathrm{CI}$ 1.31-11.78), and the analysis also revealed that increased nocturnal DBP compared to daytime DBP (non-dipping) as well as reduced nocturnal DBP dipping (0-10\% reduction compared to daytime DBP) increased the likelihood of OSA by 2.7 and 3.5 times, respectively [47].

\section{Sex Steroids}

According to the Wisconsin Sleep Cohort Study, men are 2-4 times more likely to have OSA compared to women [48], and progesterone and estrogen may play an important protective role. Sex steroids are neurosteroids that readily cross the blood-brain barrier, where they regulate respiratory function by binding to various receptors including $\mathrm{GABA}_{\mathrm{A}}$, NDMA, serotonergic receptors, and neurokinin-1 receptors in the pre-Bötzinger complex [10]. In menstruating women, elevated progesterone levels during the luteal phase are correlated with hyperventilation and hypocapnia [10], thus augmenting the arousal response to transient hypoventilation and hypercapnia associated with apneic episodes. The progesterone-mediated effects on respiratory physiology occur independent of sex. One study found that male rats given synthetic progestin had higher respirations per minute compared to untreated male rats [10]. Estrogen increases the sensitivity of ventilatory centers [10], reducing the hypercapnic threshold at which reflexive hyperventilation occurs. In one study, post-menopausal women with reduced estrogen levels were three times more likely to have OSA compared to pre-menopausal women with higher estrogen levels, and those post-menopausal women taking hormone replacement therapy (HRT) were four times less likely to have OSA compared to those not receiving HRT [49].

The primary source of estrogen and progesterone in women is the gonads (ovaries), whereas in men, only about $20 \%$ of estrogen and progesterone are produced in the gonads (testes). The remaining circulating estrogen and progesterone in men are produced via aromatase conversion of testosterone in adipose, brain, skin, and bone tissue [50]. The precursor for this conversion is testosterone. Because the majority of testosterone in men is produced in the gonads (testes), a gonadectomy indirectly will reduce estrogen and progesterone levels, thus altering respiratory function. In an experiment on male rats, respiratory functional response to induced hypoxia was reduced following gonadectomy. The rats were then supplemented with testosterone in a form susceptible to aromatase conversion into estradiol and a form unsusceptible to aromatase activity. Only the form of testosterone susceptible to aromatase conversion into estradiol normalized respiratory functional response to induced hypoxia [51].

\section{Metabolic Derangements and the Gut Microbiome}

OSA severity is correlated with metabolic syndrome and BMI [52], both of which share a correlation with HTN. Gut dysbiosis, which occurs commonly in those with metabolic syndrome, is a focus of research in many diseases, including OSA. Chronic OSA increases nocturnal microarousals and energy expenditure, resulting in daytime cravings for energy- 
dense foods. Many of these palatable foods are high in fat, carbohydrates, and salt content, all of which modulate the gut microbiome. Neo-colonization of colonic bacteria adapts to the dietary habits and chronic hypoxia within the human host. The host immune system upregulates in response to neo-colonization of foreign microbials within the gut, and the immune derangements exacerbate OSA severity [53]. These gut microbiome changes exert an endocrine effect on neurobiological synapses within the brain by way of the gutbrain axis, resulting in altered respiratory drive and mood. A 2019 study on rats analyzed the effects of comorbid OSA and a high-salt diet (HSD), which was used to simulate HTN via osmotic water retention. Lactobacillus rhamnosus $(G G)$ colonies, which are probiotics that benefit the gut microbiome, were significantly reduced in the rats exposed to apnea and HSD [54]. Additionally, blood levels of proinflammatory trimethylamine-oxide and the Th1-related cytokine IFN- $\gamma$ were significantly increased in the rats exposed to apnea and HSD [54]. OSA and HSD also reduced blood levels of the anti-inflammatory cytokine TGF- $\beta 1$ [54]. When the experimental rats were replenished with Lactobacillus rhamnosus $(G G)$ colonies, levels of trimethylamine-oxide and the Th-1/Th-2 cytokine imbalance corrected [54].

The hypothesis that administration of prebiotics and probiotics alleviates OSA-associated HTN continues to be investigated. In a 2018 study on rats exposed to chronic intermittent nocturnal hypoxia, researchers observed that cecal acetate levels (which has a preventive effect on gut inflammation and HTN) were $48 \%$ lower in study rats with OSA that were not treated with prebiotics and probiotics. After administration of Hylon VII (prebiotic) and Clostridium butyricum (probiotic), both acetate levels and SBP normalized to match those of the control rats [55]. Hylon VII is a cornstarch resistant to human brush border enzymatic digestion. It therefore provides an available substrate for bacterial fermentation into acetic acid, a short chain fatty acid (SCFA) that improves barrier function and mucosal integrity of the gastroenteric epithelial lining while also reducing activation of neuronal microglia, which are the inflammatory cells of the CNS. The abundance of SCFA-producing bacteria was significantly lower in rats with HTN compared to normotensive rats, and neuronal microglia activation was threefold higher in rats with HTN [55].

\section{Inflammation}

Inflammatory mediators are upregulated in OSA secondary to chronic hypoxia, endothelial damage, and gut dysbiosis [44]. A 2015 meta-analysis of 18 independent studies reported that patients with OSA had significantly higher inflammatory markers and carotid-femoral pulse wave velocities (a measure of arterial stiffness) when compared to patients without OSA [44]. Inflammation is upregulated in response to hypoxia-inducible factors (HIF), which are transcribed in the presence of hypoxia [56]. HIFs are strongly associated with cancer progression and metastasis [56]. A 2019 study found that elevated transcription of HIF increases colorectal carcinoma cell growth in a hypoxia dose-dependent manner [56]. OSA-induced endothelial damage, which is also elevated in other types of sclerotic vascular disease, increases TNF- $\alpha$ transcription [57]. OSA is correlated with elevations in other inflammatory mediators, including CRP, IL-6, IL-8, ICAM, selectins, and VCAM [58]. Anti-inflammatory markers TGF- $\beta$ and component 4-binding alpha protein are reduced in OSA [57].

\section{Hyperaldosteronism}

The renin-angiotensin aldosterone system (RAAS) is upregulated secondary to SNA during nocturnal apneic events. Hyperaldosteronism correlates with $A H I$ scores, reduced oxygen saturation, and elevated nocturnal DBP compared to those with normal aldosterone levels in the setting of OSA [59, 60]. Aldosterone functions in the distal nephron tubules to resorb sodium though epithelial sodium channels, which leads to an osmotic hypervolemic state. Aldosterone also acts centrally to increase RAAS, oxidative stress, and sympathetic drive, thus functioning as a positive feedback loop [61]. Intravascular fluid retention widens the transmural pressure gradient that occurs during nocturnal airway obstruction, and it increases lower leg fluid shifts in the rostral direction while recumbent. Studies on hypervolemia correction in patients with OSA and ESRD reveal that accomplishing targeted dry weights during dialysis modalities correlates inversely with OSA severity, and nocturnal peritoneal dialysis (NPD) confers better dry weight optimization compared to hemodialysis [62]. Angiotensin receptor blockers (ARBs) are effective at reducing aldosterone effects in patients with primary hyperaldosteronism, but comorbid OSA challenges this approach. A 2016 study revealed that reduction in aldosterone levels after ARB therapy was stunted in patients with concomitant OSA, but the stunted effect was ameliorated when concomitant CPAP therapy was used with the ARB therapy [63]. This same study found that CPAP therapy together with ARB therapy also reduced sympathetic noradrenaline levels compared to ARB therapy alone [63], indicating that the OSA-induced SNA may cause hyperaldosteronism resistance to ARB therapy. Because OSA confounds hyperaldosteronism, the Endocrine Society released a 2016 update to primary hyperaldosteronism screening that now includes all patients with concomitant HTN and OSA. 


\section{Hypercortisolism}

Hypercortisolism, OSA, and obesity are interconnected. Obesity, particularly in the setting of OSA, stimulates cortisol production. Adipose tissue generates active cortisol from inactive cortisone using $11 \beta$-hydroxysteroid dehydrogenase-1 (11HSD1), which is a bidirectional enzyme that also upregulates glucocorticoid receptors and promotes adipocyte hypertrophy, thus exacerbating weight gain [64]. The location of excess adipose tissue may play a role in cortisol metabolism. Urinary cortisol excretion is higher when adipose tissue is centralized to the abdomen as opposed to the peripheral body [64]. When glucocorticoid production exceeds glucocorticoid receptor availability, these steroid hormones begin binding to mineralocorticoid receptors, thus acting as aldosterone agonists and favoring fluid retention [64].

Hypercortisolism downregulates vasodilators, including prostacyclin, kallikrein-kinins, and nitric oxide. Conversely, calcium mobilization and myofilament calcium sensitivity in cardiac myocytes are upregulated, resulting in long-term cardiac remodeling and elevated risk for acute coronary syndromes (ACS) [64]. In the general population of people without OSA, the most likely time for any person to suffer from an acute myocardial infarction is between 6 a.m. and 11 a.m., which is the time when cortisol levels are the highest (in the morning) [65]. Only 7\% of people without OSA have myocardial infarctions between the hours of midnight and 6 a.m. $(P=0.01)$, whereas $32 \%$ of people with OSA will experience ACS during these nocturnal hours due to pathologically elevated cortisol levels that occur in OSA $(P=0.01)$ [66].

\section{Cardiac Remodeling}

Concentric hypertrophy is significantly associated with OSA. The odds ratio of concentric left ventricular hypertrophy in those with OSA compared to those without OSA is 1.62 (95\% CI 1.27-2.07, $P<0.0001$ ) [67••]. Left ventricular mass, wall thickness, and right ventricular area increase as oxygen desaturation worsens [68]. Interestingly, moderate sleep apnea $(A H I=15-30$ events $/ \mathrm{h})$ has a lower hazard ratio than mild sleep apnea $(A H I=5-15$ events/h) with regard to cardiovascular disease [69], highlighting the protective effect that "ischemic conditioning" plays on cardiovascular fitness [70]. When the left anterior descending artery was occluded in an experiment on rats exposed to chronic intermittent hypoxia $(\mathrm{CIH})$ compared to control rats, the rats exposed to $\mathrm{CIH}$ rats had smaller myocardial infarct size and less tachyarrhythmias [71]. The "ischemic conditioning" effect is due to neovascularization of collateral vessels in response to cardiomyocyte ischemia. Another study in rats found that after ACS, capillary density was increased by
$60 \%$ in the peri-infarct zone and VEGF was increased by $134 \%$ [72].

\section{Elevated Carbonic Anhydrase Activity}

Carbonic anhydrase compensates for respiratory acidosis secondary to apnea-related hypercapnia by upregulating resorption of bicarbonate in the proximal nephron. Arterial bicarbonate concentration is positively correlated with OSA severity independent of HTN [73, 74]. In one 2020 study on patients with OSA, $A H I$ reductions correlated with reductions in venous bicarbonate concentrations $(r=0.66$, $P=0.013$ ) [75]. Carbonic anhydrase inhibitors perpetuate respiratory acidosis during apneic events by eliminating the compensatory ability for the kidneys to reabsorb bicarbonate. The lingering acidemia stimulates respiratory drive to breathe off the excess carbon dioxide, thus correcting the apneic episode and hypercarbia. A 2020 study on participants with OSA found that acetazolamide (a carbonic anhydrase inhibitor which also functions as a weak vasodilator via calcium-activated potassium channels) reduces $A H I$ and $B P$ with or without concomitant CPAP therapy [75]. This identifies carbonic anhydrase inhibitors as a potential frontline treatment for OSA and associated HTN.

\section{Treatment}

The treatment of OSA-associated HTN includes continuous positive airway pressure (CPAP), weight loss (with reported efficacy matching that of CPAP) [35], diuretics [76], renal sympathetic denervation [77], carotid artery stenting [46], maxillomandibular advancement devices, hypoglossal nerve stimulation [78], surgical operation for restricted airways or tonsillar enlargement, and dialysis in those patients with ESRD and hypervolemia. While antihypertensive drugs are important in $B P$ control for all patients with HTN, those in whom OSA is the sole contributor to HTN might benefit from alternative interventions focused on correcting nocturnal apneic episodes. Nevertheless, antihypertensive agents, particularly ACE inhibitors, show favorable efficacy in patients with OSA-associated HTN $[79,80]$.

\section{CPAP}

CPAP delivers continuous, positively pressurized air into the distal alveoli of the respiratory tree, which maintains alveolar patency. CPAP reduces arterial stiffness, reduces HTN, and improves vascular inflammation in those with OSA $[81,82 \bullet$. The variable reductions in SBP and DBP range from -2 to $-9 \mathrm{mmHg}$ and -2 to $-7 \mathrm{mmHg}$, respectively $[35,42 \bullet \bullet, 62,83-86]$. A reduction in SBP of $2-3 \mathrm{mmHg}$ is 
associated with a $4-8 \%$ mortality reduction [42••]. Those prescribed CPAP for OSA are 2.4 times more likely to have a nocturnal non-dipping $B P$ pattern when compared to those not receiving CPAP therapy for OSA (aOR: $2.4,95 \% \mathrm{CI}$ $1.2-5.1, P=0.02$ ) [87]. This study also found a significant correlation between CPAP usage and reductions in 24-h MAP, SBP, and DBP [87]. Best results for quality of life improvements and optimal reductions in blood pressure occur when CPAP usage exceeds 4 h per night $[88,89]$. Despite the reported utility of CPAP for OSA, 39-50\% of patients prescribed nocturnal CPAP for OSA are noncompliant with usage [42••]. One study reported that $63 \%$ of patients prescribed CPAP reported feeling claustrophobic while using the machine [90]. When patients are not adherent to their CPAP prescriptions, there are increased incidence adverse outcomes, including cerebrovascular events (HR: 3.1, 95\% CI 1.07-15.1, $P=0.041$ ) and hypertensive crises (HR: 5.1, 95\% CI 2.2-11.6, $P=0.006$ ) [91].

\section{Diuretics}

Diuretic therapy reduces the intravascular hypervolemia observed in OSA-associated HTN. Diuretics reduce extracellular fluid by $10-12 \%$ within a few weeks of treatment initiation [76]. In a 2014 study of uncontrolled hypertensives with $A H I>20$ events/h, patients received an initial PSG study followed first by seven days of low-dose diuretic therapy ( $2.5 \mathrm{mg}$ metolazone and $25 \mathrm{mg}$ spironolactone), then seven days of doubled dosages, and finally a repeat PSG study at the end of the trial [92]. On repeat PSG compared to initial testing, $A H I$ decreased from $57.7 \pm 33.0$ to $48.5 \pm 28.2$ events/h $(P=0.005)$ [92]. Net change in lower leg fluid volume reduced from $-418.1 \pm 177.5$ to $-307.5 \pm 161.9 \mathrm{~mL}(P<0.001)$, and overnight change in neck circumference reduced from $1.2 \pm 0.6$ to $0.7 \pm 0.4 \mathrm{~cm}$ $(P<0.001)$ [92]. The study found that higher fluid shifts from the lower legs to the rostrum during recumbency (indicated by greater overnight change in lower leg fluid volume) correlated with higher morning SBP. Reduction in overnight change in leg fluid volume from the initial PSG to the final PSG was positively correlated with the morning change in $\operatorname{SBP}(r=0.708$, $P=0.002)$ and DBP $(r=0.512, P=0.043)$ [92]. In a different study on spironolactone in participants with r-HTN and OSA with an $A H I>15$ events/h, participants received 8 weeks of daily $20-25 \mathrm{mg}$ spironolactone therapy, and $\mathrm{AHI}$ reduced from $39.8 \pm 19.5$ to $22.0 \pm 6.8$ events/h $(P<0.05)$ [93]. Weight and ABPM were also significantly reduced [93]. In a third study of eplerenone for OSA management, three months of therapy led to reduced $A H I$, neck circumference, ABPM, aortic pulse waves, and arterial wall stiffness [94]. $A H I$ decreased from 49.5 events/h (95\% CI: $20.1-63.3, P<0.05)$ to 28.7 events/h $(95 \%$ CI: $15.7-40.3, P<0.05)[94]$.

\section{Conclusions}

OSA can surreptitiously contribute to CVD and HTN in the absence of clinical suspicion and screening. Earlier OSA diagnosis and management confers better outcomes in HTN management, morbidity, and mortality. Diagnostic tests for OSA are expanding, now including HBST and ODR. Recent data shows that shortened sleep duration in those with OSA should merit HTN investigation. A study from 2019 identified that shortened sleep duration of 5-6 h per night in those with OSA increases the odds of having HTN by $45 \%$ (OR: $1.45,95 \%$ CI 1.14-1.84), and these odds increase to $80 \%$ (OR: 1.80, 95\% CI 1.33-2.42) when sleep duration is $<5 \mathrm{~h}$ [95]. The most studied treatment option for symptomatic control of OSA is CPAP, though it has variable effects on OSA-associated HTN. HTN in those with OSA is responsive to antihypertensive therapy, diuretic therapy, nocturnal peritoneal or hemodialysis, carbonic anhydrase inhibitors, renal artery denervation, probiotics and weight loss. With multiple screening options for diagnosis and multiple mechanisms to target for treatment, OSA is a manageable disease that warrants clinical consideration, particularly due to its morbid association with HTN and CVD.

The substantial impact of OSA extends beyond the realm of disease. The healthcare market is markedly impacted, too. In 2015, OSA and its related outcomes accounted for $\$ 12.4$ billion US healthcare dollars among the 5.9 million US adults diagnosed with the sleep disorder [96]. The estimated yearly expenses related to OSA increase to approximately $\$ 49.5$ billion when the projected 23.5 million Americans undiagnosed with OSA are considered [96]. The authors of a 2015 American Academy of Sleep Medicine report on OSA healthcare costs ranked OSA-associated outcomes by the millions of people affected and by the billions of dollars expensed. Mental health disease (8.7 million people) was most expensive ( $\$ 7.1$ billion), followed by heart disease (3.1 million people; $\$ 6.7$ billion), diabetes (5.6 million people; $\$ 6.4$ billion), HTN (14.1 million people; $\$ 5.4$ billion), asthma/breathing disorders (5.9 million people; $\$ 2.6$ billion), and insomnia (6.8 million people; $\$ 2.1$ billion) [96]. Early recognition and treatment of OSA will improve patient outcomes, mitigate healthcare expenses, and alleviate the substantial burden of hypertensive disease.

\section{Compliance with Ethical Standards}

Ethical Approval Not applicable.

Consent to Participate Not applicable.

Consent for Publicationt Not applicable.

Conflict of Interest The authors declare no competing interests. 
Human and Animal Rights This article does not contain any studies with human or animal subjects performed by any of the authors.

\section{References}

Papers of particular interest, published recently, have been highlighted as:

- Of importance

$\bullet$ Of major importance

1. Seetho IW, Wilding JP. Screening for obstructive sleep apnoea in obesity and diabetes - potential for future approaches. Eur J Clin Invest. 2013;43(6):640-55. https://doi.org/10.1111/eci.12083.

2. Alakuijala A, Maasilta P, Bachour A. The Oxford Sleep Resistance test (OSLER) and the Multiple Unprepared Reaction Time Test (MURT) detect vigilance modifications in sleep apnea patients. J Clin Sleep Med. 2014;10(10):1075-82. https://doi. org/10.5664/jcsm.4104.

3. Hohl M, Linz B, Böhm M, Linz D. Obstructive sleep apnea and atrial arrhythmogenesis. Curr Cardiol Rev. 2014;10(4):362-8. https://doi.org/10.2174/1573403x1004140707125137.

4. Hsu HC, Chen NH, Ho WJ, Lin MH. Factors associated with undiagnosed obstructive sleep apnoea among hypertensive patients: a multisite cross-sectional survey study in Taiwan. J Clin Nurs. 2018;27(9-10):1901-12. https://doi.org/10.1111/ jocn. 14366

5.•• Osman AM, Carter SG, Carberry JC, Eckert DJ. Obstructive sleep apnea: current perspectives. Nat Sci Sleep. 2018;10:21-34. https:// doi.org/10.2147/NSS.S124657. This review includes an excellent summary of approaches used for the treatment of Obstructive Sleep Apnea.

6. Berry RB, Budhiraja R, Gottlieb DJ, Gozal D, Iber C, Kapur $\mathrm{VK}$, et al. Rules for scoring respiratory events in sleep: update of the 2007 AASM manual for the scoring of sleep and associated events. Deliberations of the sleep apnea definitions task force of the American academy of sleep medicine. J Clin Sleep Med. 2012;8(5):597-619. https://doi.org/10.5664/jcsm.2172.

7. Laratta CR, Ayas NT, Povitz M, Pendharkar SR. Diagnosis and treatment of obstructive sleep apnea in adults. CMAJ. 2017;189(48):E1481-8. https://doi.org/10.1503/cmaj.170296.

8. Lopez PP, Stefan B, Schulman CI, Byers PM. Prevalence of sleep apnea in morbidly obese patients who presented for weight loss surgery evaluation: more evidence for routine screening for obstructive sleep apnea before weight loss surgery. Am Surg. 2008;74(9):834-8.

9. Mokros Ł, Kuczyński W, Franczak Ł, Białasiewicz P. Morning diastolic blood pressure may be independently associated with severity of obstructive sleep apnea in nonhypertensive patients: a cross-sectional study. J Clin Sleep Med. 2017;13(7):905-10. https://doi.org/10.5664/jcsm.6664. This publication discusses the association of OSA with morning diastolic hypertension in a cross-sectional study.

10. Behan M, Wenninger JM. Sex steroidal hormones and respiratory control. Respir Physiol Neurobiol. 2008;164(1-2):213-21. https://doi.org/10.1016/j.resp.2008.06.006.

11. Chung F, Yegneswaran B, Liao P, Chung SA, Vairavanathan S, Islam S, et al. STOP questionnaire: a tool to screen patients for obstructive sleep apnea. Anesth. 2008;108(5):812-21. https:// doi.org/10.1097/ALN.0b013e31816d83e4.

12. Chung F, Subramanyam R, Liao P, Sasaki E, Shapiro C, Sun Y. High STOP-BANG score indicates a high probability of obstruc- tive sleep apnoea. Surv of Anesthesiol 2012;56(6). https://doi. org/10.1097/01.SA.0000422018.88507.a1.

13. Alhouqani S, Manhali M, Essa A, Al-Houqani M. Evaluation of the Arabic version of STOP-Bang questionnaire as a screening tool for obstructive sleep apnea. Sleep Breath. 2015;19(4):1235-40. https:// doi.org/10.1007/s11325-015-1150-x.

14. Pavarangkul T, Jungtrakul T, Chaobangprom P, Nitiwatthana L, Jongkumchok W, Morrakotkhiew W, et al. The Stop-Bang questionnaire as a screening tool for obstructive sleep apnea-induced hypertension in Asian population. Neurol Int. 2016;8(1). https:// doi.org/10.4081/ni.2016.6104.

15. Corral J, Sánchez-Quiroga MÁ, Carmona-Bernal C, SánchezArmengol Á, de la Torre AS, Durán-Cantolla J, et al. Conventional polysomnography is not necessary for the management of most patients with suspected obstructive sleep apnea. Noninferiority, randomized controlled trial. Am J Respir Crit Care Med. 2017;196(9):1181-90. https://doi.org/10.1164/rccm.201612-2497OC.

16. Grote L, McNicholas WT, Hedner J, ESADA collaborators. Sleep apnoea management in Europe during the COVID19 pandemic: data from the European sleep apnoea database (ESADA). Eur Respir J. 2020;55(6):2001323. https://doi.org/ 10.1183/13993003.01323-2020.

17.•• Wang N, Meng Z, Ding N, Chen W, Zhang X, Huang M, et al. Oxygen desaturation rate as a novel intermittent hypoxemia parameter in severe obstructive sleep apnea is strongly associated with hypertension. J Clin Sleep Med. 2020;16(7):1055-62. https://doi.org/10. $5664 / \mathrm{jcsm} .8396$. The authors have proven that the oxygen desaturation rate is closely associated with hypertension in patients with OSA.

18. Jhamb M, Unruh M. Bidirectional relationship of hypertension with obstructive sleep apnea. Curr Opin Pulm Med. 2014;20(6):558-64. https://doi.org/10.1097/MCP.0000000000000102.

19. Martynowicz H, Skomro R, Gać P, Mazur G, Porębska I, Bryłka $\mathrm{A}$, et al. The influence of hypertension on daytime sleepiness in obstructive sleep apnea. J Am Soc Hypertens. 2017;11(5):295302. https://doi.org/10.1016/j.jash.2017.03.004.

20.• Bouloukaki I, Grote L, McNicholas WT, Hedner J, Verbraecken J, Parati G, et al. Mild obstructive sleep apnea increases hypertension risk, challenging traditional severity classification. J Clin Sleep Med. 2020;16(6):889-898. https://doi.org/10.5664/jcsm. 8354. In this analysis of the relationship between mild OSA and hypertension, the authors conclude that hypertension is starting in OSA patients with five apneic events per hour.

21. Hou H, Zhao Y, Yu W, Dong H, Xue X, Ding J, Xing W, Wang W. Association of obstructive sleep apnea with hypertension: a systematic review and meta-analysis. J Glob Health. 2018;8(1): 010405. https://doi.org/10.7189/jogh.08.010405.

22. Peppard PE, Young T, Palta M, Skatrud J. Prospective study of the association between sleep-disordered breathing and hypertension. N Engl J Med. 2000;342(19):1378-84. https://doi.org/ 10.1056/NEJM200005113421901.

23. Mills KT, Stefanescu A, He J. The global epidemiology of hypertension. Nat Rev Nephrol. 2020;16(4):223-37. https://doi.org/ 10.1038/s41581-019-0244-2.

24. Baguet JP, Hammer L, Lévy P, Pierre H, Rossini E, Mouret S, et al. Night-time and diastolic hypertension are common and underestimated conditions in newly diagnosed apnoeic patients. J Hypertens. 2005;23(3):521-7. https://doi.org/10.1097/01.hjh. $0000160207.58781 .4 \mathrm{e}$.

25. Chobanian AV, Bakris GL, Black HR, Cushman WC, Green LA, Izzo JL Jr, et al. The seventh report of the joint national committee on prevention, detection, evaluation, and reatment of high blood pressure: the JNC 7 report. J Am Med Assoc. 2003;289(19):2560 72. https://doi.org/10.1001/jama.289.19.2560.

26. Young T, Evans L, Finn L, Palta M. Estimation of the clinically diagnosed proportion of sleep apnea syndrome in middle-aged 
men and women. Sleep. 1997;20(9):705-6. https://doi.org/10. 1093/sleep/20.9.705.

27. Senaratna CV, Perret JL, Lodge CJ, Lowe AJ, Campbell BE, Matheson MC, et al. Prevalence of obstructive sleep apnea in the general population: a systematic review. Sleep Med Rev. 2017;34:70-81. https://doi.org/10.1016/j.smrv.2016.07.002.

28.• Jinchai J, Khamsai S, Chattakul P, Limpawattana P, Chindaprasirt J, Chotmongkol V, et al. How common is obstructive sleep apnea in young hypertensive patients? Intern Emerg Med. 2020. https://doi.org/10.1007/s11739-019-022733. This publication has found a high prevalence of OSA in hypertensive patients younger than 35 years old.

29. Pedrosa RP, Drager LF, Gonzaga CC, Sousa MG, de Paula LK, Amaro AC, et al. Obstructive sleep apnea: the most common secondary cause of hypertension associated with resistant hypertension. Hypertens. 2011;58(5):811-7. https://doi.org/10.1161/ HYPERTENSIONAHA.111.179788.

30. Pimenta E, Calhoun DA. Resistant hypertension: incidence, prevalence, and prognosis. Circ. 2012;125(13):1594-6. https:// doi.org/10.1161/CIRCULATIONAHA.112.097345.

31. Logan AG, Perlikowski SM, Mente A, Tisler A, Tkacova R, Niroumand M, et al. High prevalence of unrecognized sleep apnoea in drug-resistant hypertension. J Hypertens. 2001;19(12):2271-7. https://doi.org/10.1097/00004872-200112000-00022.

32. Nicholl DDM, Ahmed SB, Loewen AHS, Hemmelgarn BR, Sola DY, Beecroft JM, et al. Declining kidney function increases the prevalence of sleep apnea and nocturnal hypoxia. Chest. 2012;141(6):1422-30. https://doi.org/10.1378/chest.11-1809.

33. Abdel-Kader K, Dohar S, Shah N, Jhamb M, Reis SE, Strollo $\mathrm{P}$, et al. Resistant hypertension and obstructive sleep apnea in the setting of kidney disease. J Hypertens. 2012;30(5):960-6. https://doi.org/10.1097/HJH.0b013e328351d08a.

34. Parati G, Stergiou GS, Asmar R, Bilo G, de Leeuw P, Imai Y, et al. European society of hypertension guidelines for blood pressure monitoring at home: a summary report of the second international consensus conference on home blood pressure monitoring. J Hypertens. 2008;26(8):1505-26. https://doi.org/ 10.1097/HJH.0b013e328308da66.

35. Baguet JP, Lévy P, Barone-Rochette G, Tamisier R, Pierre H, Peeters M, et al. Masked hypertension in obstructive sleep apnea syndrome. J Hypertens. 2008;26(5):885-92. https://doi.org/10. 1097/hjh.0b013e3282f55049.

36. Konecny T, Kara T, Somers VK. Obstructive sleep apnea and hypertension: an update. Hypertension. 2014;63(2):203-9. https://doi.org/10.1161/HYPERTENSIONAHA.113.00613.

37. Dempsey JA, Veasey SC, Morgan BJ, O’Donnell CP. Pathophysiology of sleep apnea. Physiol Rev. 2010;90(1):47-112. https://doi.org/10.1152/physrev.00043.2008.

38. Chouchou F, Pichot V, Pépin JL, Tamisier R, Celle S, Maudoux $\mathrm{D}$, et al. Sympathetic overactivity due to sleep fragmentation is associated with elevated diurnal systolic blood pressure in healthy elderly subjects: the PROOF-SYNAPSE study. Eur Heart J. 2013;34(28):2122-31. https://doi.org/10.1093/eurheartj/eht208.

39. Monahan KD, Leuenberger UA, Ray CA. Effect of repetitive hypoxic apnoeas on baroreflex function in humans. J Physiol. 2006;574(Pt 2):605-13. https://doi.org/10.1113/jphysiol.2006.108977.

40. Zhang J, Ma RC, Kong AP, So WY, Li AM, Lam SP, et al. Relationship of sleep quantity and quality with 24 -hour urinary catecholamines and salivary awakening cortisol in healthy middleaged adults. Sleep. 2011;34(2):225-33. https://doi.org/10.1093/ sleep/34.2.225.

41. Narkiewicz K, Montano N, Cogliati C, Van de Borne PJ, Dyken ME, Somers VK. Altered cardiovascular variability in obstructive sleep apnea. Circulation. 1998;98:1071-7.

42.•• Venkataraman S, Vungarala S, Covassin N, Somers VK. Sleep apnea, hypertension and the sympathetic nervous system in the adult population. J Clin Med. 2020;9(2):591. https://doi.org/10. $3390 / \mathrm{jcm} 9020591$. Excellent review of the role of cardiovascular variability chemorceptor activation and sympathic nervous systm in patients with sleep apnea, cardiovascular disease, and hypertension.

43. Hla KM, Young T, Finn L, Peppard PE, Szklo-Coxe M, Stubbs M. Longitudinal association of sleep-disordered breathing and nondipping of nocturnal blood pressure in the Wisconsin sleep chort study. Sleep. 2008;31(6):795-800. https://doi.org/10.1093/ sleep/31.6.795.

44. Wang J, Yu W, Gao M, Zhang F, Gu C, Yu Y, et al. Impact of obstructive sleep apnea syndrome on endothelial function, arterial stiffening, and serum inflammatory markers: an updated meta-analysis and metaregression of 18 studies. J Am Heart Assoc. 2015;4(11): e002454. https://doi.org/10.1161/jaha.115. 002454.

45. Hoyos CM, Melehan KL, Liu PY, Grunstein RR, Phillips CL. Does obstructive sleep apnea cause endothelial dysfunction? A critical review of the literature. Sleep Med Rev. 2015;20:15-26. https://doi.org/10.1016/j.smrv.2014.06.003.

46. Köklü E, Yüksel İÖ, Arslan Ş, Bayar N, Köklü F, Erkal Z, et al. Effects of carotid stenting on nocturnal nondipping phenomenon. J Stroke Cerebrovasc Dis. 2015;24(9):2102-9. https://doi.org/10. 1016/j.jstrokecerebrovasdis.2015.05.018.

47. Genta-Pereira DC, Furlan SF, Omote DQ, Giorgi DMA, Bortolotto LA, Lorenzi-Filho G, Drager LF. Nondipping blood pressure patterns predict obstructive sleep apnea in patients undergoing ambulatory blood pressure monitoring. Hypertension. 2018;72(4):979-85. https://doi.org/10.1161/HYPERTENSIONAHA.118.11525 PMID: 30354706.

48. Peppard PE, Young T, Barnet JH, Palta M, Hagen EW, Hla KM. Increased prevalence of sleep-disordered breathing in adults. Am J Epidemiol. 2013;177(9):1006-14. https://doi.org/10.1093/aje/ kws342.

49. Galvan T, Camuso J, Sullivan K, Kim S, White D, Redline S, et al. Association of estradiol with sleep apnea in depressed perimenopausal and postmenopausal women: a preliminary study. Menopause. 2017;24(1):112-7. https://doi.org/10.1097/GME. 0000000000000737.

50. Cooke PS, Nanjappa MK, Ko C, Prins GS, Hess RA. Estrogens in Male Physiology. Physiol Rev. 2017;97(3):995-1043. https:// doi.org/10.1152/physrev.00018.2016.

51. Zabka AG, Mitchell GS, Behan M. Conversion from testosterone to estradiol is required to modulate respiratory long-term facilitation in male rats. J Physiol. 2006;576(3):903-12. https://doi. org/10.1113/jphysiol.2006.114850.

52. Zhao X, Xu H, Zou J, Qian Y, Yi H, Guan J, et al. Joint interaction effect of metabolic syndrome and obstructive sleep apnea on hypertension. J Clin Hypertens. 2018;20(8):1203-12. https:// doi.org/10.1111/jch.13322.

53. Mashaqi S, Gozal D. Obstructive sleep apnea and systemic hypertension: gut dysbiosis as the mediator? J Clin Sleep Med. 2019;15(10):1517-27. https://doi.org/10.5664/jcsm.7990.

54. Liu J, Li T, Wu H, Shi H, Bai J, Zhao W, et al. Lactobacillus rhamnosus GG strain mitigated the development of obstructive sleep apnea-induced hypertension in a high salt diet via regulating TMAO level and CD4+ T cell induced-type I inflammation. Biomed Pharmacother. 2019;112: 108580. https://doi.org/10. 1016/j.biopha.2019.01.041.

55. Ganesh BP, Nelson JW, Eskew JR, Ganesan A, Ajami NJ, Petrosino JF, et al. Prebiotics, probiotics, and acetate supplementation prevent hypertension in a model of obstructive sleep apnea. Hypertension. 2018;72(5):1141-50. https://doi.org/ 10.1161/HYPERTENSIONAHA.118.11695.

56. Martinez CA, Kerr B, Jin C, Cistulli PA, Cook KM. Obstructive sleep apnea activates HIF-1 in a hypoxia dose-dependent 
manner in HCT116 colorectal carcinoma cells. Int J Mol Sci. 2019;20(2):445. https://doi.org/10.3390/ijms20020445.

57. Horvath P, Tarnoki DL, Tarnoki AD, Karlinger K, Lazar Z, Losonczy G, et al. Complement system activation in obstructive sleep apnea. J Sleep Res. 2018;27(6). https://doi.org/10.1111/jsr. 12674.

58. Nadeem R, Molnar J, Madbouly EM, Nida M, Aggarwal S, Sajid $\mathrm{H}$, et al. Serum inflammatory markers in obstructive sleep apnea: a meta-analysis. J Clin Sleep Med. 2013;9(10):1003-12. https:// doi.org/10.5664/jcsm.3070.

59. Pratt-Ubunama MN, Nishizaka MK, Boedefeld RL, Cofield SS, Harding SM, Calhoun DA. Plasma aldosterone is related to severity of obstructive sleep apnea in subjects with resistant hypertension. Chest. 2007;131(2):453-9. https://doi.org/10. 1378/chest.06-1442.

60. Goodfriend TL, Calhoun DA. Resistant hypertension, obesity, sleep apnea, and aldosterone: theory and therapy. Hypertens. 2004;43(3):518-24. https://doi.org/10.1161/01.HYP.00001 16223.97436.e5.

61. Barbot M, Ceccato F, Scaroni C. The pathophysiology and treatment of hypertension in patients with Cushing's syndrome. Front Endocrinol (Lausanne). 2019;10:321. https://doi.org/10.3389/ fendo.2019.00321.

62. Tang SCW, Lam B, Ku PP, Leung WS, Chu CM, Ho YW, et al. Alleviation of sleep apnea in patients with chronic renal failure by nocturnal cycler-assisted peritoneal dialysis compared with conventional continuous ambulatory peritoneal dialysis. J Am Soc Nephrol. 2006;17(9):2607-16. https://doi.org/10.1681/asn. 2005090936.

63. Thunström E, Manhem K, Yucel-Lindberg T, Rosengren A, Lindberg C, Peker Y. Neuroendocrine and inflammatory responses to losartan and continuous positive airway pressure in patients with hypertension and obstructive sleep apnea. A randomized controlled trial. Ann Am Thorac Soc. 2016 Nov;13(11):2002-2011. https://doi.org/10.1513/AnnalsATS. 201602-126OC. PMID: 27548072.

64. Varughese A, Nimkevych O, Uwaifo G. Hypercortisolism in obesity-associated hypertension. Curr Hypertens Rep. 2014;16(7):1-10. https://doi.org/10.1007/s11906-014-0443-y.

65. Sert-Kuniyoshi F, Pusalavidyasagar S, Singh P, Somers V. Cardiovascular consequences of obstructive sleep apnoea. Indian $\mathbf{J}$ Med Res. 2010;131:196-205.

66. Kuniyoshi FH, Garcia-Touchard A, Gami AS, Romero-Corral A, Van der Walt C, Pusalavidyasagar S, et al. Day-night variation of acute myocardial infarction in obstructive sleep apnea. J Am Coll Cardiol. 2008;52:343-6.

67.•• Cuspidi C, Tadic M, Sala C, Gherbesi E, Grassi G, Mancia G. Targeting concentric left ventricular hypertrophy in obstructive sleep apnea syndrome. A meta-analysis of echocardiographic studies. Am J Hypertens. 2020;33(4):310-15. https://doi.org/10.1093/ajh/hpz198. Using a metanalyses of electrocardiographic studies in many patients with OSA the authors have shown an increased risk of both concentric and eccentric left ventricular hypertrophy.

68. Korcarz CE, Peppard PE, Young TB, Chapman CB, Hla KM, Barnet JH, et al. Effects of obstructive sleep apnea and obesity on cardiac remodeling: the Wisconsin sleep cohort study. Sleep. 2016;39(6):1187-95. https://doi.org/10.5665/sleep.5828.

69. Hla KM, Young T, Hagen EW, Stein JH, Finn LA, Nieto FJ, et al. Coronary heart disease incidence in sleep disordered breathing: the Wisconsin sleep cohort study. Sleep. 2015;38(5):677-84. https://doi.org/10.5665/sleep.4654.

70. Ozeke O, Ozer C, Gungor M, Celenk MK, Dincer H, Ilicin G. Chronic intermittent hypoxia caused by obstructive sleep apnea may play an important role in explaining the morbidity-mortality paradox of obesity. Med Hypotheses. 2011;76:61-3.
71. Neckar J, Ostadal B, Kolar F. Myocardial infarct size-limiting effect of chronic hypoxia persists for five weeks of normoxic recovery. Physiol Res. 2004;53:621-8.

72. Xu WQ, Yu Z, Xie Y, Huang GQ, Shu XH, Zhu Y, et al. Therapeutic effect of intermittent hypobaric hypoxia on myocardial infarction in rats. Basic Res Cardiol. 2011;106:329-42.

73. Eskandari D, Zou D, Grote L, Schneider H, Penzel T, Hedner J. Independent associations between arterial bicarbonate, apnea severity and hypertension in obstructive sleep apnea. Respir Res. 2017;18(1):1-9. https://doi.org/10.1186/s12931-017-0607-9.

74. Hoff E, Zou D, Schiza S, Demir Y, Grote L, Bouloukaki I, et al. Carbonic anhydrase, obstructive sleep apnea and hypertension: effects of intervention. J Sleep Res. 2020;29(2). https://doi.org/ 10.1111/jsr.12956.

75. Eskandari D, Zou D, Grote L, Hoff E, Hedner J. Acetazolamide reduces blood pressure and sleep-disordered breathing in patients with hypertension and obstructive sleep apnea: a randomized controlled trial. J Clin Sleep Med. 2018;14(3):309-17. https://doi.org/10.5664/jcsm.6968.

76. Fiori CZ, Martinez D, Montanari CC, Lopez P, Camargo R, Sezerá L, et al. Diuretic or sodium-restricted diet for obstructive sleep apnea—a randomized trial. Sleep. 2018;41(4). https://doi. org/10.1093/sleep/zsy016.

77. Linz D, Mancia G, Mahfoud F, Narkiewicz K, Ruilope L, Schlaich $\mathrm{M}$, et al. Renal artery denervation for treatment of patients with selfreported obstructive sleep apnea and resistant hypertension: results from the global sympliticity registry. J Hypertens. 2017;35(1):14853. https://doi.org/10.1097/hjh.0000000000001142.

78. Lee CH, Seay EG, Walters BK, Scalzitti NJ, Dedhia RC. Therapeutic positive airway-pressure level predicts response to hypoglossal nerve stimulation for obstructive sleep apnea. J Clin Sleep Med. 2019;15(8):1165-72. https://doi.org/10.5664/jcsm. 7814.

79. Weichler U, Herres-Mayer B, Mayer J, Weber K, Hoffmann R, Peter JH. Influence of antihypertensive drug therapy on sleep pattern and sleep apnea activity. Cardiol. 1991;78(2):124-30. https://doi.org/10.1159/000174776.

80. Peter JH, Gassel W, Mayer J, Herrer-Mayer B, Penzel T, Schneider $\mathrm{H}$, et al. Effects of cilazapril on hypertension, sleep, and apnea. Am J Med. 1989;87(6B):72S-78S.

81. Lin X, Chen G, Qi J, Chen X, Zhao J, Lin Q. Effect of continuous positive airway pressure on arterial stiffness in patients with obstructive sleep apnea and hypertension: a meta-analysis. Eur Arch Otorhinolaryngol. 2016;273(12):4081-8. https://doi.org/ 10.1007/s00405-016-3914-8.

82.• Tokunou T, Ando S. Recent advances in the management of secondary hypertension-obstructive sleep apnea. Hypertens Res. 2020. https://doi.org/10.1038/s41440-020-0494-1. The authors have analyzed the importance of OSA treatments in the patient's hypertension control.

83. Iftikhar IH, Valentine CW, Bittencourt LR, Cohen DL, Fedson AC, Gíslason T, et al. Effects of continuous positive airway pressure on blood pressure in patients with resistant hypertension and obstructive sleep apnea: a meta-analysis. J Hypertens. 2014;32(12):2341-50. https://doi.org/10.1097/HJH.0000000000000372.

84. Huang Z, Liu Z, Luo Q, Zhao Q, Zhao Z, Ma X, et al. Long-term effects of continuous positive airway pressure on blood pressure and prognosis in hypertensive patients with coronary heart disease and obstructive sleep apnea: a randomized controlled trial. Am J Hypertens. 2015;28(3):300-6. https://doi.org/10.1093/ajh/ hpu147.

85. Marin JM, Carrizo SJ, Vicente E, Agusti AGN. Long-term cardiovascular outcomes in men with obstructive sleep apnoea-hypopnoea with or without treatment with continuous positive airway pressure: an observational study. Lancet. 2005;365(9464):1046-53. https:// doi.org/10.1016/s0140-6736(05)71141-7. 
86. Muxfeldt ES, Margallo V, Costa LM, Guimarães G, Cavalcante $\mathrm{AH}$, Azevedo JC, et al. Effects of continuous positive airway pressure treatment on clinic and ambulatory blood pressures in patients with obstructive sleep apnea and resistant hypertension: a randomized controlled trial. Hypertens. 2015;65(4):736-42. https://doi.org/10.1161/HYPERTENSIONAHA.114.04852.

87. Martínez-García MA, Capote F, Campos-Rodríguez F, Lloberes P, Díaz de Atauri MJ, Somoza M, et al. Effect of CPAP on blood pressure in patients with obstructive sleep apnea and resistant hypertension: the HIPARCO randomized clinical trial. J Am Med Assoc. 2013;310(22):2407-15. https://doi.org/10.1001/ jama.2013.281250.

88. McEvoy RD, Antic NA, Heeley E, Luo Y, Ou Q, Zhang X, et al. CPAP for prevention of cardiovascular events in obstructive sleep apnea. N Engl J Med. 2016;375(10):919-31. https://doi. org/10.1056/NEJMoa1606599.

89. Bratton DJ, Gaisl T, Wons AM, Kohler M. CPAP vs mandibular advancement devices and blood pressure in patients with obstructive sleep apnea: a systematic review and meta-analysis. J Am Med Assoc. 2015;314(21):2280-93. https://doi.org/10.1001/ jama.2015.16303.

90. Edmonds JC, Yang H, King TS, Sawyer DA, Rizzo A, Sawyer AM. Claustrophobic tendencies and continuous positive airway pressure therapy non-adherence in adults with obstructive sleep apnea. Heart Lung J Crit Care. 2015;44(2):100-6. https://doi. org/10.1016/j.hrtlng.2015.01.002.

91. Navarro-Soriano C, Martínez-García MA, Torres G, Barbé F, Sánchez-de-la-Torre M, Caballero-Eraso C, et al. Longterm effect of treatment on cardiovascular events in patients with resistant hypertension and sleep apnea. Data from the HIPARCO-2 study. Arch Bronconeumol. 2020 Feb
3:S0300-2896(19)30612-X. https://doi.org/10.1016/j.arbres. 2019.12.006.

92. Kasai T, Bradley TD, Friedman O, Logan AG. Effect of intensified diuretic therapy on overnight rostral fluid shift and obstructive sleep apnoea in patients with uncontrolled hypertension. J Hypertens. 2014;32(3):673-80. https://doi.org/10.1097/HJH. 0000000000000047.

93. Gaddam K, Pimenta E, Thomas SJ, Cofield SS, Oparil S, Harding SM, et al. Spironolactone reduces severity of obstructive sleep apnoea in patients with resistant hypertension: a preliminary report. J Hum Hypertens. 2009;24(8):532-7. https://doi.org/10.1038/jhh. 2009.96.

94. Krasińska B, Miazga A, Cofta S, Szczepaniak-Chicheł L, Trafas T, Krasiński Z, et al. Effect of eplerenone on the severity of obstructive sleep apnea and arterial stiffness in patients with resistant arterial hypertension. Pol Arch Intern Med. 2017;126(5):330-9. https://doi. org/10.20452/pamw.3410.

95. Ren R, Covassin N, Yang L, Li Y, Zhang Y, Zhou J, et al. Objective but not subjective short sleep duration is associated with hypertension in obstructive sleep apnea. Hypertens. 2018;72(3):610-7. https://doi.org/10.1161/HYPERTENSIONAHA.118.11027.

96. Frost \& Sullivan. Darien, IL: American Academy of Sleep Medicine; 2016. Hidden health crisis costing America billions. Underdiagnosing and undertreating obstructive sleep apnea draining healthcare system. Available from: http://www.aasmnet.org/sleepapnea-economic-impact.aspx.

Publisher's Note Springer Nature remains neutral with regard to jurisdictional claims in published maps and institutional affiliations. 